\title{
Is Medical Concern about Hookah Environmental Tobacco Smoke Hazards Warranted?
}

\author{
Kamal Chaouachi*
}

Tobacco Researcher and Consultant, DIU Tabacologie, Paris XI University, France

\begin{abstract}
This paper reviews the present knowledge about the nature of hookah (narghile, shisha) ETS and, in the light of the controversy over the actual health effects of cigarette ETS, concludes that the former should not be hyperbolised in an unscientific way as, unfortunately, a WHO report suggests.
\end{abstract}

Key Words: Smoking, tobacco, diseases, ETS (environmental tobacco smoke), hookah, shisha.

\begin{abstract}
Environemental Tobacco Smoke in Italian and French literature:
"Qui venivano gli amici, e anch'essi si buttavano e, come diceva Muscarà, s'abbiavanu e sdavacàvanu, sui pagliericci e le ciambele di cuoio, rimpiendo presto la camera di un tale fumo di sigareta che, dal balcone socchiuso, i passanti vedevano uscire una sorta di lenzuolo grigio palpitante nell'aria. Fumo, caffè, e liquori... »

(Vitaliano Brancati, 1940)

"...sous les treilles aux pampres frais, sous les glycines, sous les platanes; des narguilés par myriades, le long des rues, exhalaient leur fumée enjôleuse. "
\end{abstract}

\section{A Tribute to Gian Turci}

(Pierre Loti, 1904)

\section{INTRODUCTION}

Hookah (narghile, shisha) smoking is seen as a global tobacco epidemic and there is definitely a lack of sound studies on the hazards related to its active smoking [1]. Amazingly, and as if hookah and cigarette smoking were similar, more and more biomedical publications report hazards related to its ETS (environmental tobacco smoke).

Not only is the model of cigarette smoking irrelevant but it has proved to be highly controversial. In the USA, Enstrom and Kabat found no causal relation between ETS and mortality related to smoking [2]. The publication of the corresponding results raised so many adverse reactions that the first author felt he had to publish a defence of them [3]. More recently, in Europe, the situation has reached the point that a not less renowned scholar literally asks about an official supranational public health report that has remained uncommented for years: "Epidemiological Study or Manipulation ?". The scientist was amazed by official statistics reporting a large increase of the death toll related to passive smoking in Europe. He found that among the 5863 estimated deaths, 4749 concerned everyday smokers. Furthermore, the 1114 "non-smokers" included all former smokers as well. Obviously, the remaining risk of the latter cannot be attributed to ETS [4].

Unfortunately, the concern over hookah ETS has been growing in such a context and has apparently found its fuel there. A World Health Organisation expert report states that

\footnotetext{
*Address correspondence to this author at the Tobacco Researcher and Consultant, DIU Tabacologie, Paris XI University, France; E-mail:kamcha@gmail.com
}

1874-0766/09 "second-hand smoke from waterpipes $[\ldots]$ poses a serious risk for non-smokers" $[1,5]$. Such a statement is supported by a publication of the US-Syrian Centre for Tobacco Studies and the report was co-authored by two members of the latter. More recently, a review published by an international team of researchers has echoed the same motto [6].

Unfortunately, if, in cigarettes, ETS is a "sum" of EMS (Exhaled Mainstream smoke) and SSS (Side-Stream Smoke), the situation is completely different with hookah smoking because this kind of pipe generates almost no SSS (Figs. 1 and 2). The main reason is that the tobacco-molasses based mixture is not burnt as in cigarettes but only heated whereby temperatures barely go beyond $150^{\circ} \mathrm{C}$ or $200^{\circ} \mathrm{C}[1$, 7]. ETS in hookah smoking is actually reduced to EMS to a great extent, i.e. to a smoke whose toxicity is very low because it has undergone extra filtration in the respiratory tract in which on average, $60-80 \%$ of the particulate matter is retained [8]. The percentages for volatile aldehydes and polycyclic aromatic hydrocarbons are even higher. As for carbon monoxide, generated by the charcoal, a reference study shows that expired mean $\mathrm{CO}$ levels in non-smokers exposed to hookah smoke virtually do not vary [9]. Finally, in order to help clearing up confusion, it is worth recalling that hookah smoke is far less complex than that generated by cigarettes. Indeed, there would be one or a few hundred compounds in the former [10]. By comparison, the latter has been thoroughly studied so far and contains about 4,700 compounds [8].

\section{CONCLUSION}

The hazards of cigarette ETS have been widely hyped as prestigious scholars have shown $[2,4]$. Concern about those 


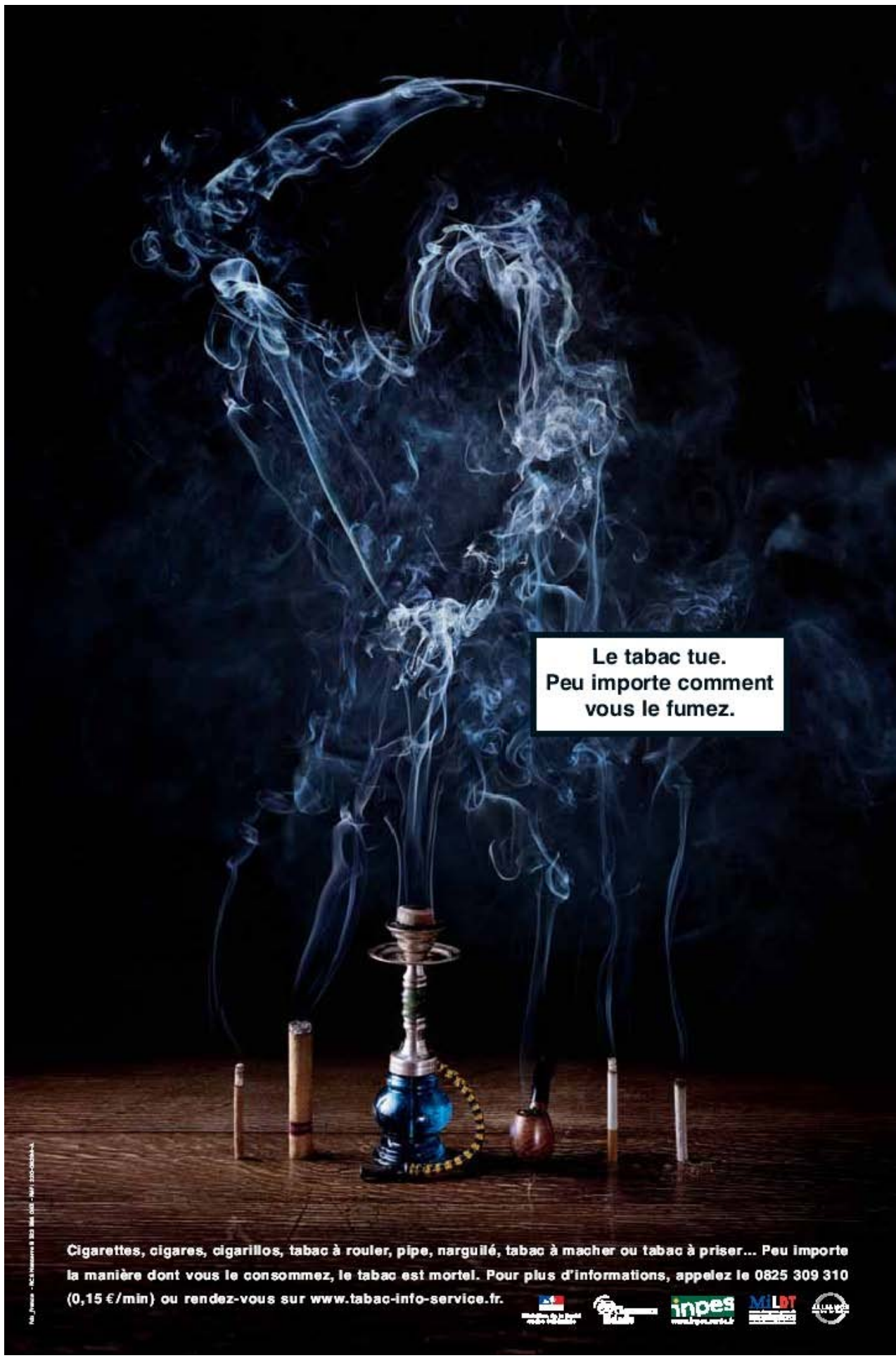

Fig. (1). Poster of the French INPES (Institut National pour la Prevention et l'Education a la Santé). This visual aid was used during the 2005 "World Not Tobacco Day" campaign sponsored by the WHO. It shows a huge cloud of dense smoke (supposedly "ETS") stemming from a hookah and featuring the spectrum of death. Unfortunately, a hookah does not generate such a side-stream smoke.

from hookah ETS is even more unwarranted in the light of the state-of-the-art science.

\section{COMPETING INTERESTS}

The author has no competing interests to declare. He has unfortunately never received direct or indirect funding either from pharmaceutical companies (nicotine "replacement" therapies and products) or from the tobacco industry. Ten years ago, he measured $\mathrm{CO}$ levels in French hookah lounges and issued recommendations that, unfortunately for the world public health, were never taken into account. For this reason, he participated, from Spring to Autumn 2004, in the development of a No-CO harm reduction patented hookah which cuts down CO by $95 \%$. He signed away all his rights 
on June 15,2005 . He began to publish studies in peerreviewed biomedical journals only beyond that date.

\section{$\because$ AMERICAN LUNG ASSOCIATION. Tobacco Policy Trend Alert}

\section{AN EMERGING DeAdly TREND:WATERPIPE TOBACCO Use February 2007}

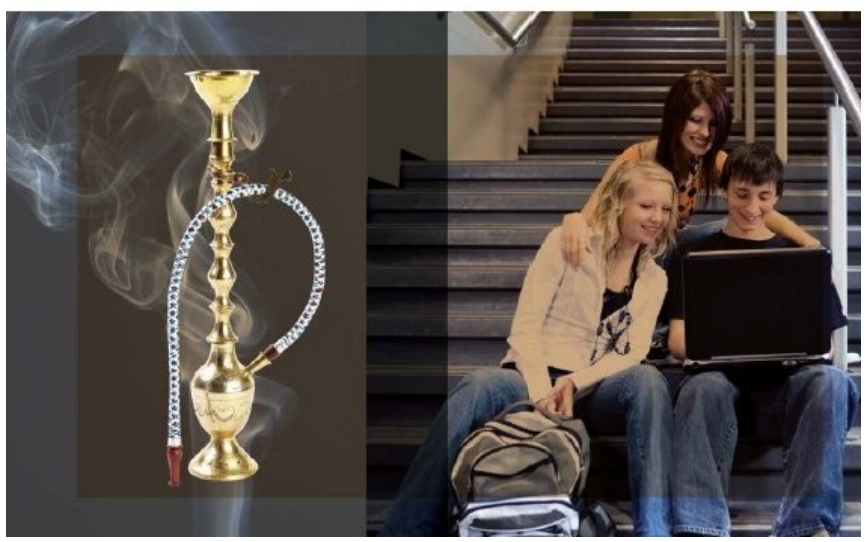

Fig. (2). Cover of the American Lung Association's report on "“waterpipe"”. It shows a small-size hookah generating SSS on its own. Unfortunately, a hookah does not generate such a side-stream smoke.

\section{REFERENCES}

[1] Chaouachi K. A Critique of the WHO's TobReg "Advisory Note" entitled: "Waterpipe Tobacco Smoking: Health Effects, Research Needs and Recommended Actions by Regulators" (2005). J Negat Results Biomed 2006 (17 Nov); 5: 17. http://www.jnrbm.com/ content/pdf/1477-5751-5-17.pdf

[2] Enstrom JE, Kabat GC. Environmental tobacco smoke and tobacco related mortality in a prospective study of Californians 1960-98 BMJ 2003; 326: 1057

[3] Enstrom JE. Defending legitimate epidemiologic research: combating Lysenko pseudoscience. Epidemiol Perspect Innov 2007 (10 Oct); 4: 11. http://www.epi-perspectives.com/content/4/1/11

[4] Molimard R. The European Report "Lifting the SmokeScreen": Epidemiological study or manipulation?. Rev Epidemiol Sante Publique 2008 Aug; 56(4): 286-90. [English Abstract; article in French].

[5] World Health Organisation/TobReg. Waterpipe Tobacco Smoking: Health Effects, Research Needs and Recommended Actions by Regulators. Advisory Note, 2005

[6] Prignot JJ, Sasco AJ, Poulet E, Gupta PC, Aditama TY. Alternative forms of tobacco use. Int J Tuberc Lung Dis 2008; 12(7): 718-27.

[7] Sajid KM, Chaouachi K, Mahmood R. Hookah smoking and cancer: carcinoembryonic antigen (CEA) levels in exclusive/ever hookah smokers. Harm Reduct J 2008 May 24; 5: 19. http://www. harmreductionjournal.com/content/pdf/1477-7517-5-19.pdf

[8] Thielen A, Klus H, Müller L. Tobacco smoke: unraveling a controversial subject. Exp Toxicol Pathol 2008; 60(2-3): 141-56.

[9] Bacha ZA, Salameh P, Waked M. Saliva cotinine and exhaled carbon monoxide levels in natural environment waterpipe smokers. Inhal Toxicol 2007; 19(9): 771-7.

[10] El-Aasar AM, El-Merzabani MM. Studies on jurak smoke: I. The organic constitutents of jurak smoke. JKAU Sci 1991; 3: 169-81.

(C) Kamal Chaouachi; Licensee Bentham Open.

This is an open access article licensed under the terms of the Creative Commons Attribution Non-Commercial License (http: //creativecommons.org/licenses/ by-nc/3.0/) which permits unrestricted, non-commercial use, distribution and reproduction in any medium, provided the work is properly cited. 